\title{
Collecting and Managing Data
}

2005 Show-Me The Measures Summit

\author{
Jefferson City, Missouri
}

July 13, 2005

Bill Elder

University of Missouri-Columbia

Office of Social \& Economic Data Analysis (OSEDA) 


\section{Overview of Presentation}

- What are "data" and why do we care?

- The focus of performance measurement

- Collecting Data (types, methods, issues)

- Managing Data (coping with complexity)

- Discussion

Selected Sources, Links and References-web links at... www.oseda.missouri.edu 


\section{Context provides meaning and relevance to data}

- Data

- Information

- Knowledge

-Wisdom

"The construction of knowledge involves the orderly loss of information, not its mindless accumulation." Kenneth Boulding 


\section{How do we know we're asking the "right" question and answering it in the "right" way?}

We need a contextual frameworka theory of action. 


\section{Frameworks for Performance Measures and Decisions}

- Basic research

- Theories lead to hypotheses

- Policy (applied) research

- Policy frameworks focus key questions and indicator requirements 


\section{Review of some performance measurement frameworks guiding data collection choices}

- Budget guidance (State of Missouri)

- Utilization focused evaluation (Patton)

- Program logic models (Kellogg Foundation)

- Balanced score card (State of Missouri OIT)

- Local government (Fairfax County, Virginia) 


\section{Missouri State Budget Guidance Policy Measures of...}

- Effectiveness (success or impact)

- Efficiency (ratio of outputs to inputs)

- Clients/Individuals Served

- Customer Satisfaction, if available 


\section{Utilization Focused Evaluation}

- Who are the decision makers

- What are the decisions

- Reducing the risk of making decisions

There is always an implicit programmatic decision...

sustain, increase or decrease support 


\section{Evaluative Decisions (eMINTs)}

- If the students in the high-tech classrooms score better than the other students, we will expand eMINTs. (Otherwise, we will allocate resources elsewhere.)

- Because inquiry-based instruction and good tech support are critical to impact, we will monitor both and augment if needed.

Source: www.oseda.missouri.edu/educational_reports/ 


\section{The program logic model}

- The program logic model is "a picture of how your organization does its work-the theory and assumptions underlying the program."

Source: W.K. Kellogg Foundation (2004), Logic Model Development Guide, Battle Creek, Michigan. 


\section{Programs have logical (if then) relationships about which we can inquire and develop performance indicators and collect data.}

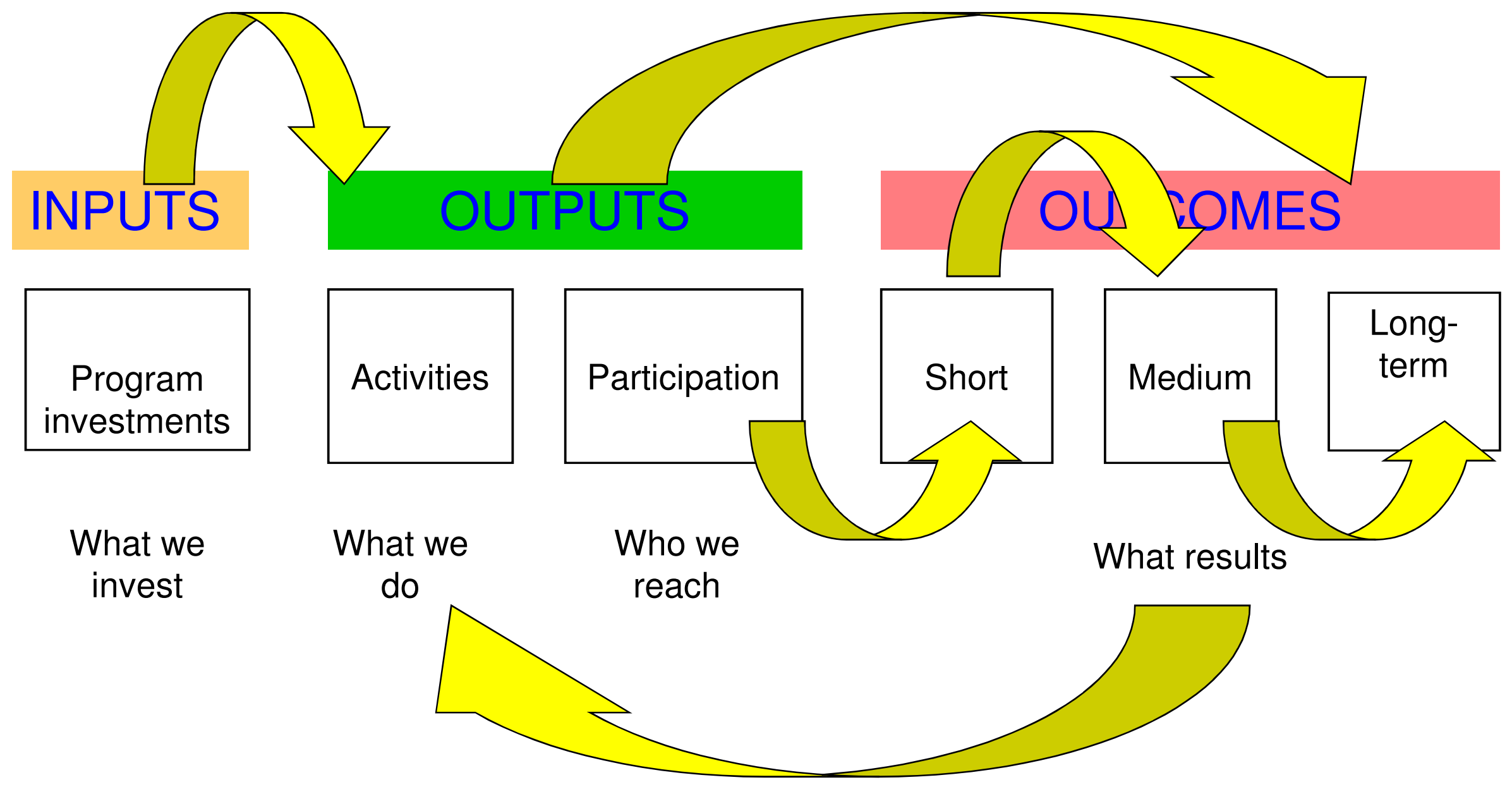




\section{Indicator strategies for elements of a program logic model}

- Resources

- Activities

- Outputs

- Outcomes \& Impacts
- Compare actual resources to anticipated

- Compare actual activities and participation levels

- Compare quality \& quantity of service delivery

- Compare baseline indicators before and after 


\section{Balanced Score Card}

- Stakeholders

- Customers

- Business Processes

- Financial Issues

- Learning \& Growth
- Objectives

- Measures

- Definition

- Targets (rubrics)

- Actions 


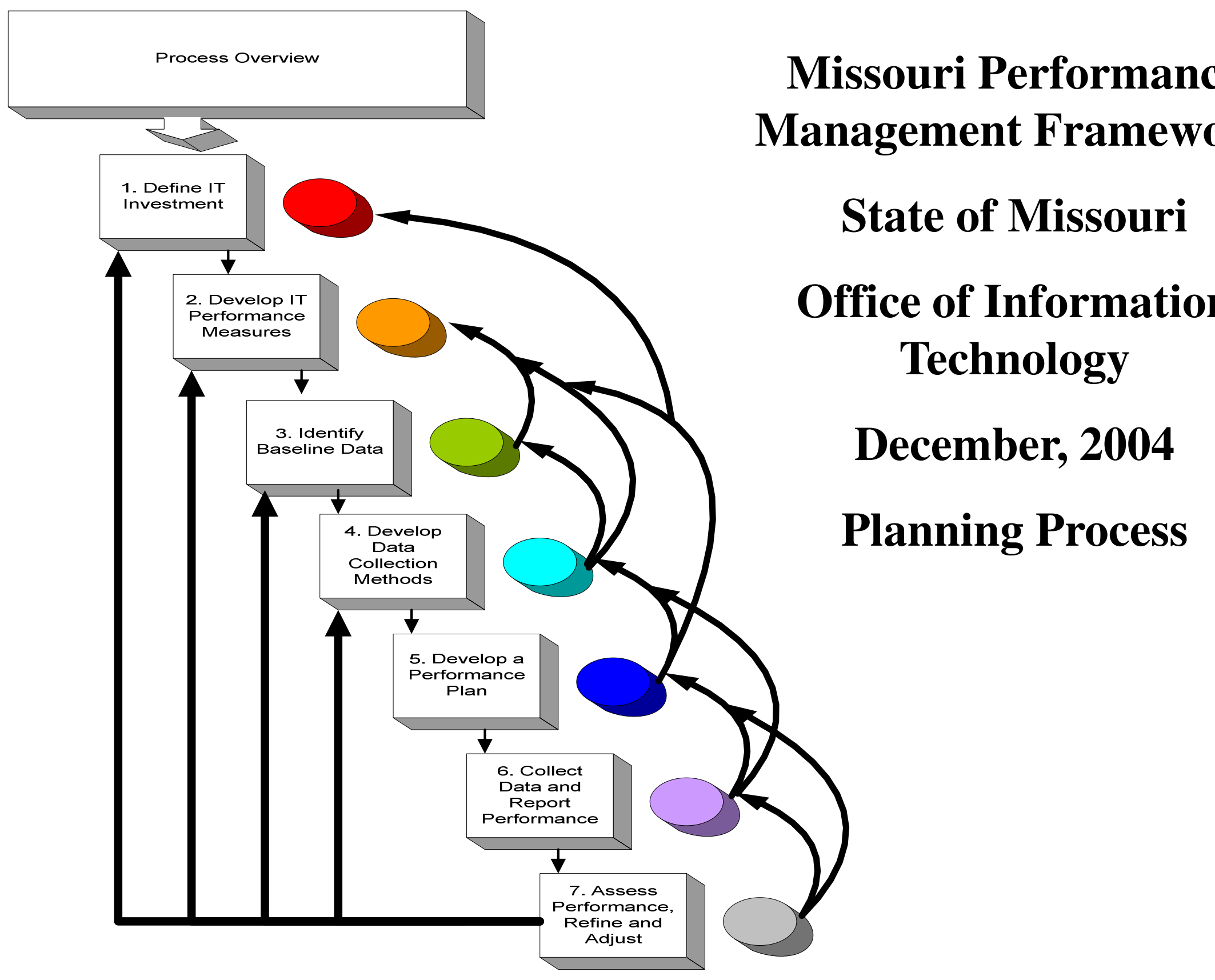




\section{Missouri, OIT Data Collection Planning Process Guides}

- Identifying data \& gathering baseline data

- Determining data availability

- Developing a data collection method

- Questions for validating data collection

Source: State of Missouri, Office of Information Technology (2004), Missouri Performance Management, Part II: Performance Management Process and Core Measures. 


\section{Fairfax County-Data Collection for Performance Measurement Process and Documentation Steps}

- Define objectives

- Design data collection process

- Test the collection method

- Gather the data

- Analyze the data

- Use the data

- Refine and improve processes
- Data Definition

- Collection Process

- Data Sources

- Data Manipulation

- Explanatory Data 


\section{So, there are many types of performance measurement frameworks}

- Budget guidance (State of Missouri)

- Utilization focused evaluation (Patton)

- Program logic models (Kellogg Foundation)

- Balanced score card (State of Missouri OIT)

- Local government (Fairfax County, Virginia) 


\section{Asking the right question in the right way: many alternative frameworks}

The point is that the meaning, usefulness and cost effectiveness of indicators depends on the indicator's connection to decisions implicit in the conceptual framework adopted by the program.

Disconnected data are not really "indicators" and rarely become "information" or "knowledge." 


\section{Asking the right question in the right way: many alternative frameworks}

The challenge is not to merely capture data, but to use "information" to manage for results.

Because data collection is often expensive, it is wise to be "connected." Good performance frameworks include planning guides to help accomplish this essential task (see links). 


\section{Dimensions of Data Collection}

- Types of Data

- Data Collection Issues

- Data Collection Strategies

- Data Collection Methods 


\section{Types of Data}

- Quantitative (counts, rates, means, closed-ended questions)

- "hard"

- Requires adequate statistical treatment

- Require clear context for interpretation

- Qualitative (focus groups, case studies, open-ended questions)

- "soft"

- Requires interpretation

- Can be powerful or perceived as self-serving 


\section{Data Collection Issues}

- Validity and Reliability

- Reproducible - transparent-public

- Consistent-accurate-precise

- Number of Cases

- Timeliness and Frequency of Measurement

- Lagging indicators

- Infrequent sources (U.S. Census) 


\section{Data Collection Issues}

- Representative Measures

- Selection bias - (intended or otherwise)

- Types of sampling (cluster, stratified)

- Confidentiality (HIPAA/IRB)

- Historical and future availability (trends)

- Disaggregation categories (NCLB)

- Security (encryption, personnel, servers) 


\section{Data Collection Strategies}

- Quality Assurance

- Field control—training

- Pilot testing

- Ongoing Monitoring

- Documentation

- Units of Analysis (smallest appropriate)

- Data linkage (merging)

- IDS and Confidentiality - extract files (without ids)

- Careful about size of files (data handling - transfers) 


\section{Data Collection Strategies}

- Proxy Measures

- "Proxy measures of health care status"

- "Mothers' level of education"

- "repeat clients"_-"customer satisfaction"

- Collaborations

- Sharing existing data files

- Bundling effort (teams, samples, infrastructure)

- MOUs

- Stratified Sampling (categories of interest) 


\section{Data Collection Methods}

$K$ Existing Data

$k$ Secondary Data Sources

$k$ (Census, MCDC, MICA, MERIC, OSEDA)

$K$ Agency Files and Records (Access)

$K$ New Data Collection (adjusting practices)

$K$ Clear planning (roles and responsibilities)

$K$ Direct Costs

$K$ Impact on Business Practices

$k$ Personnel

$K$ Impact on Transaction files 


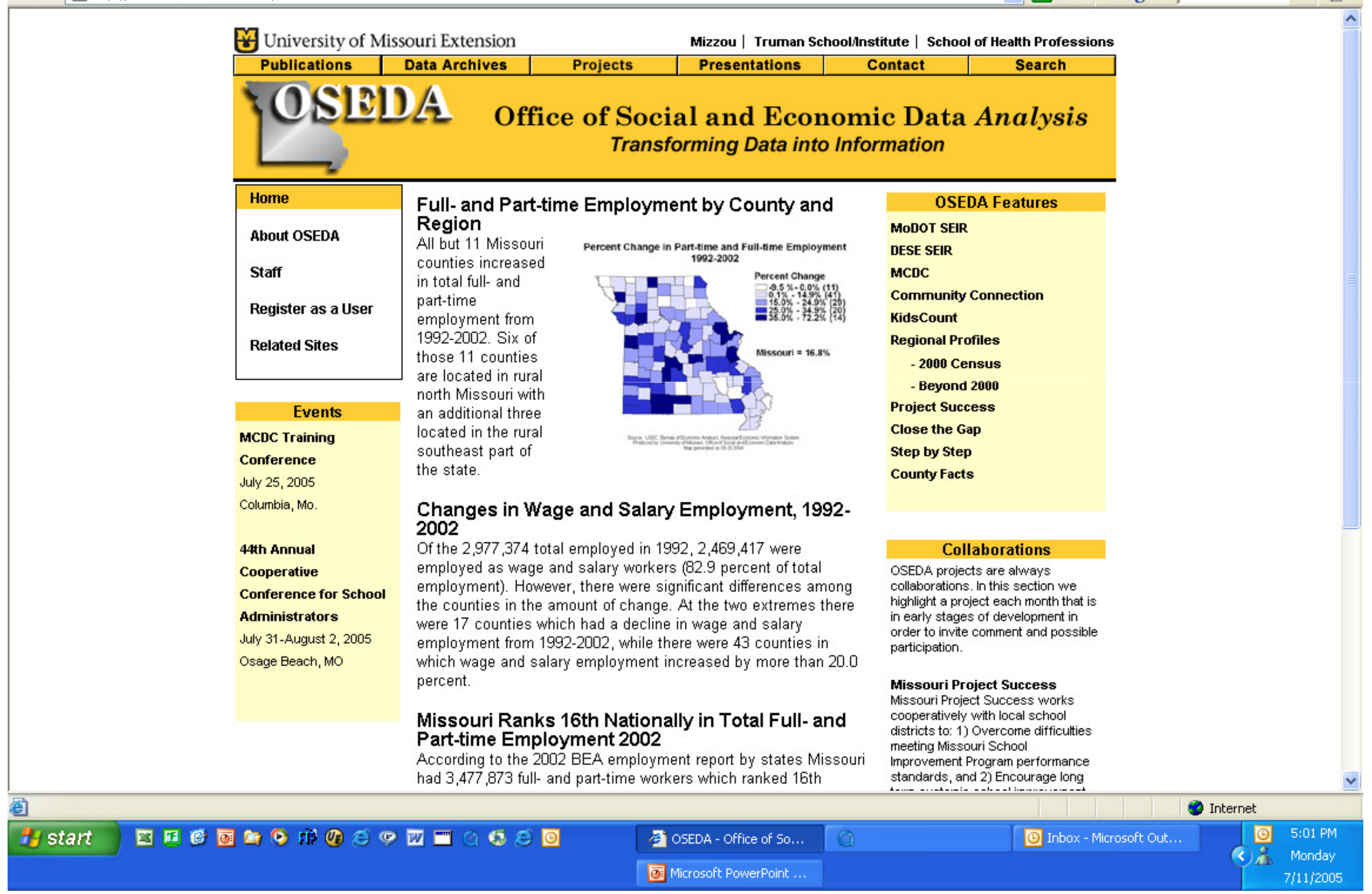




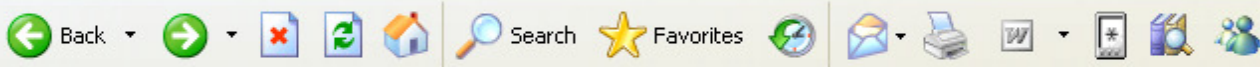

Address hettp://wwww.census.gov/prod/wwwistatistical-abstract-04.html

\section{U.S. Census Bureau}

\section{Statistical Abstract of the United States}

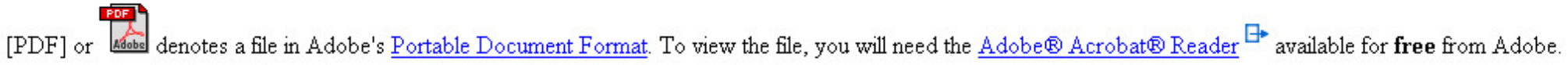

Note: If you experience diffculty printing Statistical Abstract tables to HPPCL printers, please read this technical note.

To view: $1995-2000$

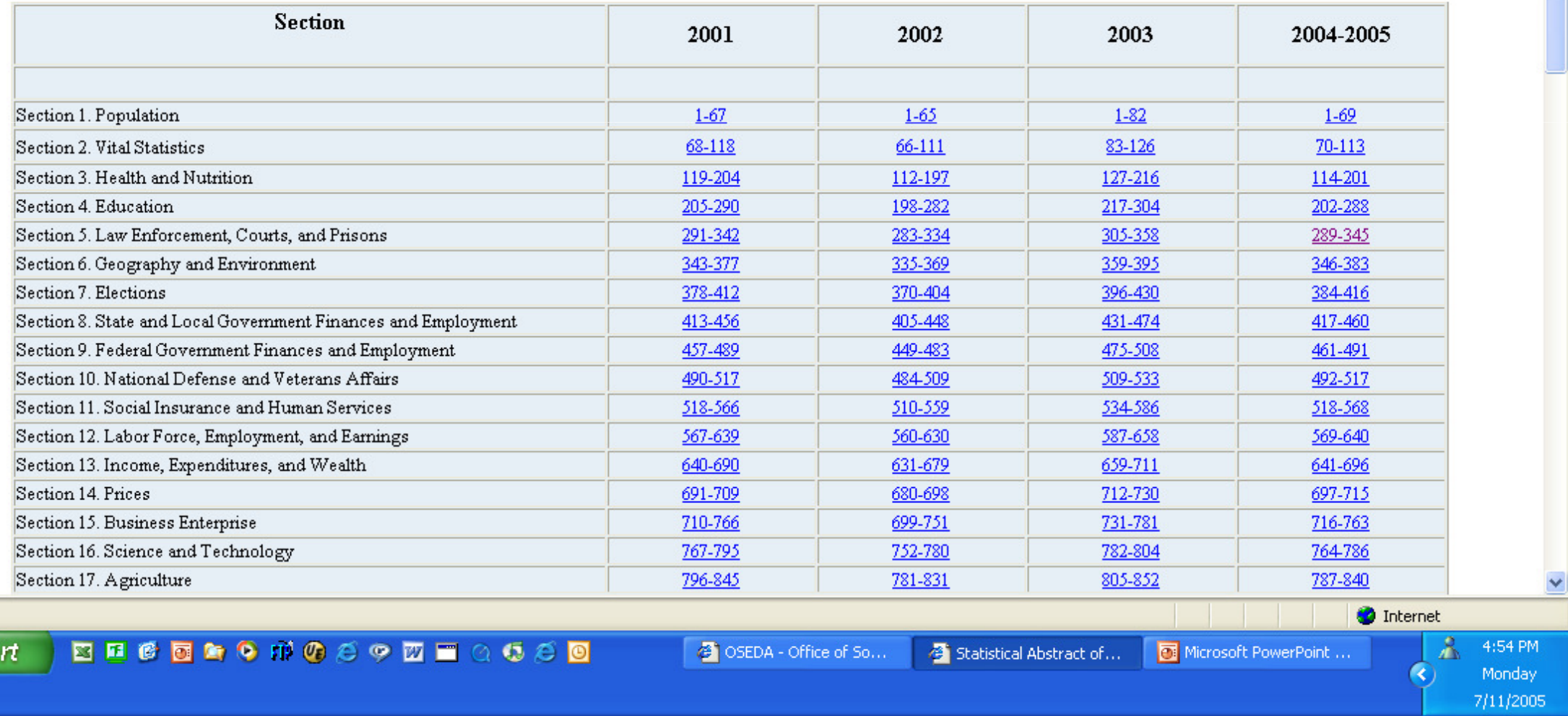




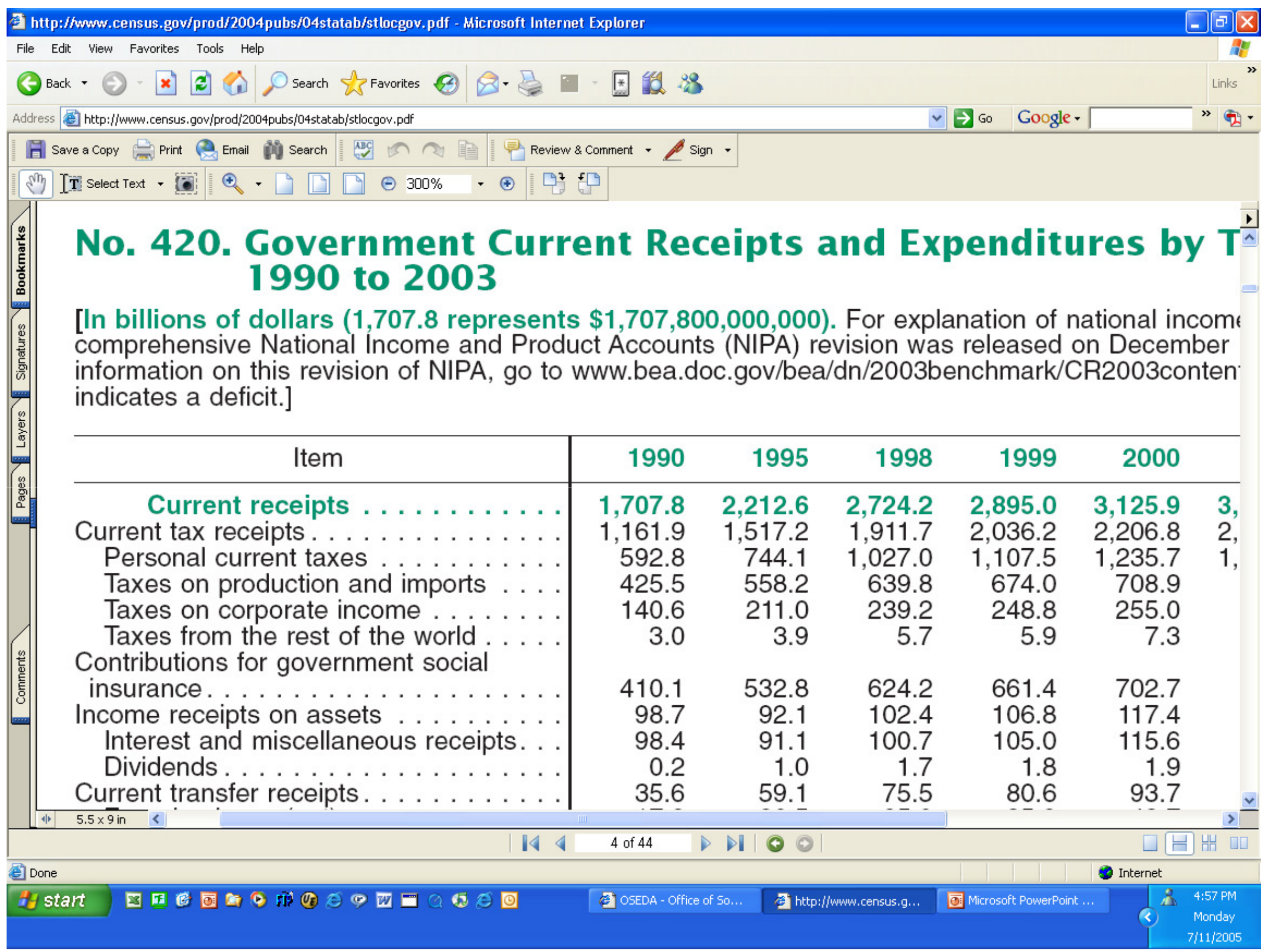




\section{Data Collection Methods}

$K$ Existing Data

$k$ Secondary Data Sources

$k$ (Census, MCDC, MICA, MERIC, OSEDA)

$K$ Agency Files and Records (Access)

$K$ New Data Collection (adjusting practices)

$K$ Clear planning (roles and responsibilities)

$K$ Direct Costs

$K$ Impact on Business Practices

$k$ Personnel

$K$ Impact on Transaction files 


\section{Data Collection Methods}

$\measuredangle$ Sample Surveys

$K$ Interviews (direct and phone)

$\measuredangle$ Questionnaires (differential response rates)

$K$ Direct Observation (protocols)

$K$ Design issues

$K$ Instrument construction

$\measuredangle$ Sampling

$\measuredangle$ Statistical Analysis and reporting

$\measuredangle$ Web Applications (Simple-Complex) 


\section{Data Collection Methods}

KQualitative Methods

$k$ Focus Groups

$K$ Case Studies

$k$ Open Ended Interviews

$K$ Design issues

$k$ "Emergent Issues"

$k$ Time frames

$k$ Representativeness

$K$ Analysis and reporting 


\section{Managing Data}

- "Only" 52 million Google hits on topic

- Scale, Complexity and Change

- The World is Flat (Thomas Friedman)

- The global integration of computing and communication technologies via the WEB with business practices...including performance measurement

- For example: SIF" -- School's Interoperability Framework -XML 


\section{Coping with Complexity}

- Build as simple a plan as possible-determine what you really need \& stick to it

- Plan all the way through analysis \& reporting

- Build a capable team to work your plan

- Consider both internal and external talent

- Adopt an appropriate approach

- e.g. Kellogg, Missouri Project Management, Balanced Score Card. 


\section{Selected Davidson's Principles}

- Back it up --- Do it now!

- You can't analyze what you don't measure.

- Take control of the structure and flow of your data-save a copy of the original data.

- Change awareness - keep a record of data changes and manipulations (diagrams help).

- Implausibility-always check for outliers.

Source: Davidson, Fred, (1996) Principals of Statistical Data Handling,

Sage Publications, Thousand Oaks, Ca. 


\section{Helpful Data Management Tools}

- Database management systems

- Pick up trucks (Access) and dump trucks (SQL)

- Design, Design and Design (Architecture)

- Statistical analysis systems (SAS, SPSS)

- Spreadsheets -- Graphics

- Geographic Information Systems (GIS)

- Web applications

- "dynamic" On-line analytical processing (OLAP)

- "dynamic looking" -- Menu guided pages with tables and charts (gif) images 


\section{Data Collection Public Resources}

- Universities

- Truman School - affiliated centers

- Extension - OSEDA

- State agencies, including..

- MERIC (DED)

- Missouri Information for Community Assessment (MICA) (DHSS)

- MCDC - Missouri Census Data Center 


\begin{tabular}{|l|l|}
\hline Home \\
About OSEDA \\
Staff \\
Register as a User \\
Related Sites \\
\hline
\end{tabular}

\section{Related Sites}

\section{Demographics}

\section{Missouri:}

Missouri Census Data Center-MCDC - is the state's official site for census-related data. It is a partner of the U.S. Census Bureau.

\section{Events}

Missouri Economic Policy and Research Center - provides a diverse database extraction system that is the basis for the Missouri Statistical Abstract for counties.

\section{MCDC Training}

Conference

Missouri Spatial Data Information Service-MSDIS - is a data retrieval and archive system that

July 25,2005 provides geographic information systems and census data about the state of Missouri to the public

Columbia, Mo.

by way of anonymous FTP and this World Wide Web site.

\section{4th Annual}

Missouri Office of Administration, Budget and Planning is home for the state demographer. In addition to releasing budget reports for the state, the official population projection estimates are housed here.

\section{Cooperative}

Conference for School

Administrators

July 31-August 2, 2005

Osage Beach, MO

Missouri Economic and Research Information Center-MERIC is an entity of the Missouri Department of Economic Development. This site provides comprehensive analysis of key economic indicators for Missouri counties by economic regions.

The Center for Agricultural, Resource and Environmental Systems-CARES - provides an interactive map utility for various social and economic indicators and has built a number of applications for analyzing different scenarios of the data. An online atlas for Missouri counties is also available from this site.

\section{Beyond Missouri:}

U.S. Census Bureau - provides results from the decennial census surveys and produces a number of indicators for public use like poverty estimates

Statistical Abstract of the United States - contains a collection of statistics on social and economic conditions in the United States. Selected international data are also included.

State Data Center Clearinghouse - provides an up-to-date account on issues and activities of the state data center participant agencies. It is a platform that provides collaboration between the 


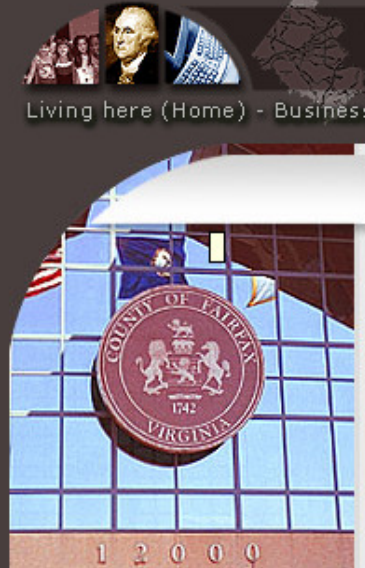

Fairfax County

- Local Government Sites

- State Government Sites

- Federal Government Sites

\section{Performance Measurement Links}

you are here: $\underline{\text { homepage }}>$ government $>\underline{\text { county budget and finance }>\text { performance measurement links }}$

This site has links to the following five categories:

- Associations, Universities and Other Sites

\section{Budget Documents}

Budget Archives

FY 2006 Adopted Budget Facts

Fr 2006 Pay Plans

Citizen's Guide To The Budgat

Overview

General Fund (Vol 1)

Capital Construction and other

Economic Indicators \& Index

Inventory of County Activities,

Carryover

Capital Improvement Program

6)

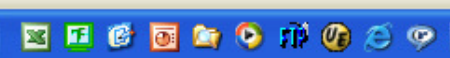

Local Government Sites

Sunnyvale, California

The Adopted Budget for 2004-2005 can be found at this site

Orange County, Florida

Performance Measurement data by department is available in the 2005 Budget. The manual for Orange County's PerformanceBased Measurement System is also available online.

Charlotte, North Carolina

Charlotte's performance measurement/management strategy involves translating mission and vision into tangible and measurable

objectives that are results-focused. The City of Charlotte's performance management approach consists of identifying organizational

strategy through Council Focus Areas and the Strategic Plan, developing the City's Balanced Scorecard, and developing Key Business

Unit and Support Business Unit business plans. The Balanced Scorecard has helped the City of Charlotte translate strategy into

actions.

Portland, Oregon

\begin{tabular}{|c|c|c|c|}
\hline (-) 6 Microsoft Office $0 . .$. & The Performance Inst.. & Ferformance Measur... & M $4: 41 \mathrm{PM}$ \\
\hline Microsoft Excel - Ban... & 빨' Document1 - Microsof.. & 6: Microsoft PowerPoint & 7/11/2005 \\
\hline
\end{tabular}




\section{Discussion -- Questions}




\title{
Collecting and Managing Data
}

2005 Show-Me The Measures Summit

\author{
Jefferson City, Missouri
}

July 13, 2005

Bill Elder

University of Missouri-Columbia

Office of Social \& Economic Data Analysis (OSEDA) 


\section{Identifying data and performing baseline:}

-Determine data requirements and information sources

-Determine data availability

-Match existing data with data requirements for measures

- Document data definitions

- Collect data if available

-Document baselines

Source: State of Missouri, Office of Information Technology (2004), Missouri Performance Management, Part II: Performance Management Process and Core Measures. 


\section{Determining data availability}

-What are the units of measure?

-What are the required data ranges?

-What is the frequency required?

-If the measure requires compilation of other data,

What are the sub-elements needed?

-If historical data is required, is it readily available?

-Who controls the data?

- Can the data be readily obtained?

\$ource: State of Missouri, Office of Information Technology (2004), Missouri Performance Management, Part II: Performance Management Process and Core Measures. 


\section{Developing a data collection method:}

-Identify sources of existing data for each measure

-Establish agreements to collect new data if necessary

-Agree upon roles and responsibilities for data collection

- Determine the impact of the data collection processes

-Document the data sources and systems

-Use automated data collection where possible

- Collect and verify data

-Evaluate relevancy and accuracy of data

Source: State of Missouri, Office of Information Technology (2004), Missouri

Performance Management, Part II: Performance Management Process and Core Measures. 


\section{Questions for validating data collection:}

-How is the measurement taken?

-Who measures?

-When (how often) are the measurements?

-Where are the measurements results sent?

-Where are the results and who is the keeper?

-What is the cost of data collection?

-Who provides the resources to collect data?

-Will data collection significantly alter existing operational processes or negatively influence those who will have to collect the data?

Source: State of Missouri, Office of Information Technology (2004), Missouri Performance Management, Part II: Performance Management Process and Core Measures. 